\title{
Electrochemical Healing Techniques for Concrete Reinforcement Restoration
}

\author{
By Tomas Lovasi* \\ Sarka Msallamova \\ Milan Kouril
}

\begin{abstract}
Electrochemical chloride extraction (ECE) from a reinforced concrete structure may be accompanied with an electrochemical injection of healing agents (EICI) if such agents are positively charged and are able to migrate towards the activated reinforcement. Positive charge carrying nanoparticles or cationic corrosion inhibitors might be the proper choice. Organic substances with a positive charge and their salts are mostly such inhibitors. In this study, critical concentration of chlorides was investigated for fresh and carbonated concrete pore solution. Corrosion inhibition efficiency was evaluated by means of polarization resistance as a measure of corrosion rate. Sodium nitrite was taken as a reference corrosion inhibitor. As a second objective were migration tests. ECE and EICI were performed in order to test the migration ability of promising cation corrosion inhibitors, namely tetrabutylammonium bromide and tetrabutylphosphonium bromide. Concentration profile of the inhibitors and chlorides was investigated in the testing concrete blocks. The best results have been obtained for tetrabutylammonium bromide.
\end{abstract}

Keywords: Chloride Extraction, Concrete, Corrosion, Electrochemical Injection.

\section{Introduction}

Corrosion of steel in concrete is a major threat to structure, especially when it is caused by chloride ions. As a result of such attack, premature failure of the reinforced concrete structure may occur. Steel embedded in chloride-free Portland cement concrete can have high corrosion resistance. The reason is that concrete provides an alkaline environment that protects steel from corrosion. This corrosion resistance consists of passive layer, which covers the steel surface after insertion into fresh concrete. Such a protective film is stable in the highly alkaline environment of fresh concrete, the $\mathrm{pH}$ of which is in the range of about 12.5-13.8. At such a high $\mathrm{pH}$ range there is availability of free oxygen in the concrete that contributes to retain; the steel is in a passive state. If the steel is placed in concrete under such conditions, corrosion rate is negligible. The main cause of passive layer break down is carbonation of the concrete and penetration of chloride ions in to the steel surface (Orellan et al., 2004). During the carbonation process, carbon dioxide penetrates through the concrete, dissolves in the concrete pore solution; and reacts

\footnotetext{
*Student, University of Chemistry and Technology, Czech Republic.

${ }^{\dagger}$ University of Chemistry and Technology, Czech Republic.

*University of Chemistry and Technology, Czech Republic.
} 
with calcium hydroxide to produce calcium carbonate. This reaction (Equation 1) leads to a reduction in the alkalinity of the concrete (Ihekwaha et al., 1996).

$\mathrm{Ca}(\mathrm{OH})_{2}+\mathrm{CO}_{2} \rightarrow \mathrm{CaCO}_{3}+\mathrm{H}_{2} \mathrm{O}$

This process does not have a significant impact on corrosive rate. Carbonation leads to changes in the structure of the concrete and the water and ions permeability (Ihekwaha et al., 1996).

Conduction of chloride ions into the concrete has little effect on $\mathrm{pH}$ change, but their presence affects the breakage of the protective layer on the steel surface. While carbonation is more likely to lead to even corrosion, chloride ions concentrate on specific locations where they indicate pitting corrosion, as to shown in the Figure 1.

Figure 1. Types of Steel Corrosion in Concrete (Vavpetic, 2008)

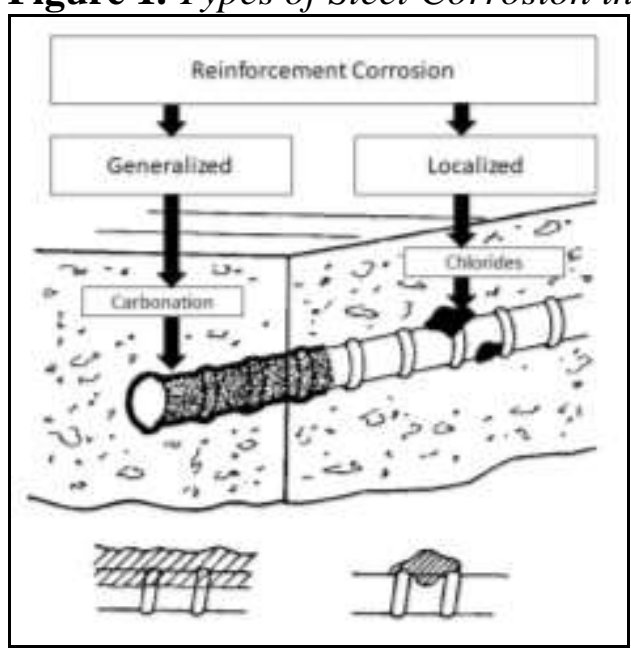

The steel corrosion process is an electrochemical process in which certain requirements must be met. One of them is a sufficient amount of dissolved oxygen, which is needed to react at cathode sites. Another requirement is to withhold moisture to maintain low electrical resistance in the concrete between the anode and the cathode sites (Karthick et al., 2016). After the initiation of the corrosion, the electrochemical process of the corrosion itself can lead to an overall deterioration of the reinforced concrete structure (Soylev and Richardson, 2008). Depending on the $\mathrm{pH}$ close to the steel surface and the availability of oxygen, corrosion of the steel reinforcements proceeds according to the reactions mentioned in Ormellese et al., 2009. Oxygen is the most harmful in this process, because without oxygen the steel reinforcement is not subject to corrosion even in the presence of aggressive ions (Ormellese et al., 2009).

During corrosion already iron corrodes, respectively oxidizes, at the anode to form ferric ions and releases two electrons (Garcia et al., 2012; Miranda et al., 2006).

$\mathrm{Fe} \rightarrow \mathrm{Fe}^{2+}+2 \mathrm{e}^{-}$ 
Released electrons flow through the steel and are combined with the presence of oxygen or humidity at the cathode to form hydroxide ions (Miranda et al., 2006; Lovasi et al., 2017).

$\mathrm{H}_{2} \mathrm{O}+1 / 2 \mathrm{O}_{2}+2 \mathrm{e}^{-} \rightarrow 2 \mathrm{OH}^{-}$

The hydroxide ions further react with ferrous ions at the anodes to form the ferrous hydroxide

$\mathrm{Fe}^{2+}+2 \mathrm{OH}^{-} \rightarrow \mathrm{Fe}(\mathrm{OH})_{2}$

Subsequently, the ferrous hydroxide can react in the presence of water to form ferric hydroxide $\mathrm{Fe}(\mathrm{OH})_{3}$ and ferric oxide $\mathrm{Fe}_{2} \mathrm{O}_{3}$. It is possible that species other than those mentioned above may be formed. As a result of these reactions, the corrosion products occupy a larger volume than the original (primary) steel, resulting in cracking or crumbling of the concrete after its tensile strength has been exceeded. The most common chloride ions come from marine environments and from mixtures that are used for road maintenance in winter (Shi et al., 2012; Fajardo et al., 2016; Yeih et al., 2006). Such accumulated chloride ions can initiate corrosion of the steel rebars if their concentration in concrete exceeds a threshold level. In various published literature, the threshold level of chloride ions is within a wide range of values (Page et al., 1986). Under normal conditions, the chloride ion threshold typically ranges from $0.2 \%$ to $0.5 \%$ by weight of cement (Gaidis, 2004; Angst et al., 2009).

In concrete, chloride ions can migrate mainly by three mechanisms. Natural diffusion, electrical migration and transport through the pore solution due to capillary forces or external pressure gradient (Kouril et al., 2017). In concrete, chloride ions move primarily by natural diffusion. When using an external electric field, the chloride ions are moved by electrical migration. The natural diffusion of chloride ions depends primarily on their concentration gradient (Pan et al., 2008). Chloride-induced corrosion of the steel rebars may be alleviated by reducing the chloride ion level in concrete using various mechanisms (Miranda et al., 2007). During the corrosion of steel reinforcement, it is possible for chloride ions to migrate from local cathodes to local anodes within the generated electric field ( $\mathrm{Li}$ and Page, 2000). Such an external electric field is most often applied to the controlled transport of chloride ions from concrete (Martinez et al., 2015). For example, electrochemical extraction of chlorides (ECE) may be a possible method (Elsener and Angst, 2007). It is possible to use cathodic protection, electrochemical chloride extraction mentioned, as well as electrochemical injection of a corrosion inhibitor (EICI) for the overall treatment of the reinforced concrete structure (Parthiban et al., 2008; Xu and Yao, 2011; Sawada et al., 2007). In order to alleviate corrosion caused by chloride ions, it is also possible to use effective chemical agents serving as corrosion inhibitors. Such inhibitors may be mixed into fresh concrete in new structures or applied to the surface, when such inhibitors are used to rehabilitate previously existing structures. In the latter case, it is 
possible to use an external electric field to drive inhibitors into concrete (Kubo et al., 2008; Gong et al., 2018).

Cathodic protection uses lower current densities $\left(15-20 \mathrm{~m} \mathrm{~A}^{-2}\right)$ that are maintained for a long period of time to prevent corrosion of the steel reinforcement in the concrete. This method also helps to prevent accumulation of chloride ions on the surface of the steel reinforcement (Pedeferri, 1996). At ECE, electric fields with a current density typically ranging from 1-5 A.m ${ }^{-2}$ are applied to the concrete structure for several weeks (Liu and Shi, 2009). Within this time period, chloride ions migrate from concrete to an external solution mostly located on the surface of the concrete in which an external anode is incorporated (Herrera et al., 2006). By using a similar set-up as in ECE, the EICI can deliver the inhibitor via concrete to the steel surface while simultaneously removing chloride ions from the concrete. EICI is a relatively new method that has recently emerged as a promising solution to corrosion for reinforcing steel in concrete structures, and also as an effective method for the addition of corrosion inhibitors for rehabilitation measures to prevent or inhibit already exiting corrosion on the surface of the steel reinforcement (Nguyen et al., 2015; Daniyal and Raja, 2016).

This method has a number of advantages, such as a non-destructive character, is a "novelty" and requires only a temporary installation (a few days). At the beginning, high potential and current density were used 5-10 V.cm ${ }^{-1}$ a $4.6-12.4$ A.m ${ }^{-2}$ (Asaro et al., 1990). Recently, the National Association of Corrosion Engineers (NACE) proposed a lower current density application. Current density values should not exceed 4 A.m ${ }^{-2}$. Over time, the conditions for the experiment have improved. Nowadays, mostly reported current densities range between 0.5 and 5 A.m ${ }^{-2}$ (Carmona et al., 2015). The Strategic Higway Research Program (SHRP) study resulted in a proposal of quaternary ammonium and phosphonium salts as corrosion inhibitors, which could be injected into the concrete by means of an electric field (Pan et al., 2008). These inhibitors are positively charged; i.e., they are cationic corrosion inhibitors. This study has proven, these corrosion inhibitors are able to reduce the adverse effects of chlorides in terms of corrosion and to provide adequate protection to steel reinforcement in concrete. Only a few new studies have been published since this study. The reason could be the high cost of corrosion inhibitors. Since then, several other studies have been conducted focusing on other types of corrosion inhibitors (Pan et al., 2008).

An example is a study examining the electromigration of two organic-based inhibitors, namely ethanolamine and guanidine (Sawada et al., 2005). In this study, the EICI process applies the electric field between a steel reinforcement embedded in concrete and the external anode (typically Ti mesh or stainless steel mesh) with a current density in the range of 1-5 A.m ${ }^{-2}$ for 3-14 days. With the same conditions, experiments were performed by applying a corrosion inhibitor in the form of an external electrolyte. However, no electric field was used. Concentration profiles induce successful injection of both inhibitors. Better effects have been achieved in carbonated concrete where inhibitors were more concentrated around the steel reinforcement. In non-carbonated concrete, treatment with guanidine injection for 2 weeks at current density 5 A.m ${ }^{-2}$ did not provide sufficient results. In this case, the inhibitor did not get deep enough. Even the injection of ethanolamine into non- 
carbonated concrete was not significantly increased by used the electric field (Sawada et al., 2005).

In another study, $\mathrm{Xu}$ et al. (2016) performed laboratory tests using triethylentetramine in chloride-contaminated concrete samples. They have used a new method called bidirectional electromigration rehabilitation (BIEM). The electric field and the corrosion inhibitor were applied in the same way as at the standard EICI method. Electrochemical chloride extraction using a saturated solution $\mathrm{Ca}(\mathrm{OH})_{2}$ as an external electrolyte was used as the reference experiment. After the treatment, the samples were drilled to determine concentration profiles of the chloride ions, hydroxide ions and corrosion inhibitor in the concrete. Using this technique, the author succeeded in reducing the chloride ions content and, after treatment, increased alkalinity in the concrete. The concentration of the corrosion inhibitor injected around the embedded steel rebars was sufficient to protect against corrosion. Kubo et al. (2013) in their contribution describe an electrochemical inhibitor injection test, which was applied to the 40-year old carbonated high-speed railway viaduct in Tokyo. The experiment found that the electrochemical injection of a corrosion inhibitor on an organic base, ethanolamine, was successful. An adequate amount of the inhibitor was penetrated into to existing railway viaduct. Inhibitor was near the steel surface for passivation of the steel in sufficient concentration under the conditions under study.

However, these methods can be used only for concrete with increased porosity. These are older constructions, where new types of concrete have not been used yet. For High Performance Concrete and Ultra High Performance Concrete, these methods are not expected to be used. The reasons are that these types of concrete have very low porosity and reduces transport of corrosive media (chloride, water, $\mathrm{CO}_{2}, \mathrm{O}_{2}$ ) in material.

The aim of this study was to investigate the corrosion inhibition efficiency of tetrabutylammonium bromide and tetrabutylphosphonium bromide as a corrosion inhibitor with prospective cationic action in alkaline concrete environment and compare their efficiency with commercially used corrosion inhibitor. Subsequently, their migration ability in concrete was proved. Other corrosion inhibitors have been evaluated in our study (Kouril et al., 2017).

\section{Experimental Part}

\section{Model Solutions and Corrosion Inhibitors}

As a model solution, a concrete pore solution of calcium hydroxide with $\mathrm{pH}$ value of 13 (adjusted with sodium hydroxide) was used to simulate the environment of fresh concrete. The other solution, a saturated solution of calcium carbonate with $\mathrm{pH}$ value of 8 was used. This solution simulates the environment of carbonated concrete. The sodium chloride was added to the saturated solution of calcium carbonate at various concentrations. To the calcium hydroxide solution, sodium chloride was added in one concentration and corrosion inhibitors were 
added at two different concentrations. The particular concentrations of chloride anions and/or corrosion inhibitors are shown in Table 1.

Table 1. Composition of the Model Solutions

\begin{tabular}{|c|c|c|}
\hline Solution & Cl content $^{-}$ & Inhibitor content \\
\hline \multirow{2}{*}{$\mathrm{Ca}(\mathrm{OH})_{2}$} & $15 \mathrm{~g} . \mathrm{l}^{-1}$ & $0.423 \mathrm{~mol} . \mathrm{l}^{-1}$ \\
\cline { 2 - 2 } & $0 \mathrm{~g} . \mathrm{l}^{-1}$ & $2.115 \mathrm{~mol} . \mathrm{l}^{-1}$ \\
\multirow{3}{*}{$\mathrm{CaCO}_{3}$} & $0.1 \mathrm{~g} . \mathrm{l}^{-1}$ & \multirow{2}{*}{$0.423 \mathrm{~mol}^{-1} \mathrm{l}^{-1}$} \\
\cline { 2 - 2 } & $1 \mathrm{~g} . \mathrm{l}^{-1}$ & \\
\cline { 2 - 3 } & $10 \mathrm{~g} . \mathrm{l}^{-1}$ & \\
\cline { 2 - 3 } & & \\
\hline
\end{tabular}

During the experiment, two cationic corrosion inhibitors and a reference inhibitor (sodium nitrite) as a representative of a well-established corrosion inhibitor for concrete were tested. All related information is summarized in Table 2. During the experiment, concentration of $0.423 \mathrm{~mol}^{-1} \mathrm{l}^{-1}$ for solution was used. This concentration was determined from the critical chloride content for activation of corrosion process. The value of critical chloride content is 0.4 weight $\%$ of $\mathrm{Cl}^{-}$ per cement, which corresponds approximately to $15 \mathrm{~g} . \mathrm{l}^{-1}$ or $0.423 \mathrm{~mol} . \mathrm{l}^{-1}$ of $\mathrm{Cl}^{-}$in concrete pore solution at normal humidity. Sodium nitrite was used only for the calcium hydroxide solution. Since this inhibitor is largely commercially used (in most cases as an additive to fresh concrete), it was not an objective to further test its inhibitory efficacy.

Table 2. Corrosion Inhibitors used in the Tests

\begin{tabular}{|c|c|c|c|c|}
\hline Name & $\begin{array}{c}\text { Chemical } \\
\text { purity [\%] }\end{array}$ & $\begin{array}{c}\text { Molar } \\
\text { Weight } \\
\text { [g.mol }^{-1} \text { ] }\end{array}$ & $\begin{array}{c}\text { pH of } \\
\text { solution }\end{array}$ & Supplier \\
\hline Sodium nitrite & $\geq 99.0$ & 69.00 & 9 & \multirow{2}{*}{$\begin{array}{c}\text { Sigma - } \\
\text { Aldrich }\end{array}$} \\
\cline { 1 - 3 } $\begin{array}{c}\text { Tetrabutylammonium } \\
\text { bromide } \\
\text { (ReagentPlus } ®)\end{array}$ & $\geq 99.0$ & 322.37 & 6.9 & \\
\cline { 1 - 3 } $\begin{array}{c}\text { Tetrabutylphosphonium } \\
\text { bromide }\end{array}$ & 98.0 & 339.33 & 4.9 & \\
\hline
\end{tabular}

\section{Concrete Specimens}

Real concrete specimens were used for an experiment of migration ability for both corrosion inhibitors. For the preparation of a cubic meter of OPC concrete specimens the components listed in Table 3 were used. From this mixture, concrete cylinder specimens (100 $\mathrm{mm}$ in diameter and $50 \mathrm{~mm}$ in height) were cast. The specimens were kept in water for 28 days. Afterwards, the specimens were dried at $105{ }^{\circ} \mathrm{C}$ overnight to stabilize their weight. Unexposed surface of the specimens was painted by a synthetic paint, IZOBAN (Detecha). Poor quality concrete was chosen on purpose to accelerate the transport processes. Water-to- 
cement ratio corresponded to 0.8 . This value corresponded to low quality of concrete. ${ }^{1}$

Table 3. Composition of OPC Concrete Cubic Meter

\begin{tabular}{|l|c|}
\hline Components & Mass [kg] \\
\hline Cement (grade CEM I 42.5R) & 262 \\
\hline Water & 210 \\
\hline Sand (grain size 4-8 mm) & 1150 \\
\hline Aggregate (grain size 4-8 mm) & 291 \\
\hline Aggregate (grain size $8-16 \mathrm{~mm}$ ) & 582 \\
\hline
\end{tabular}

\section{Steel Specimens}

The carbon steel (W.Nr. 1.0330), a ferritic-perlite steel (Figure 2) with elements content: $0.045 \% \mathrm{C}, 0.382 \% \mathrm{Mn}, 0.007 \% \mathrm{P}, 0.009 \% \mathrm{~S}$, was used. ${ }^{2}$ This carbon steel was cut in the form of strips $35 \times 175 \mathrm{~mm}$. Subsequently, these strips were degreased with a $10 \%$ sodium hydroxide solution. Subsequently, the samples were thoroughly washed with distilled water after pickling with a 5\% hydrochloric acid. The surface was polished with sandpaper P180 and rinsed with ethanol prior to exposure.

Figure 2. Microstructure of Carbon Steel

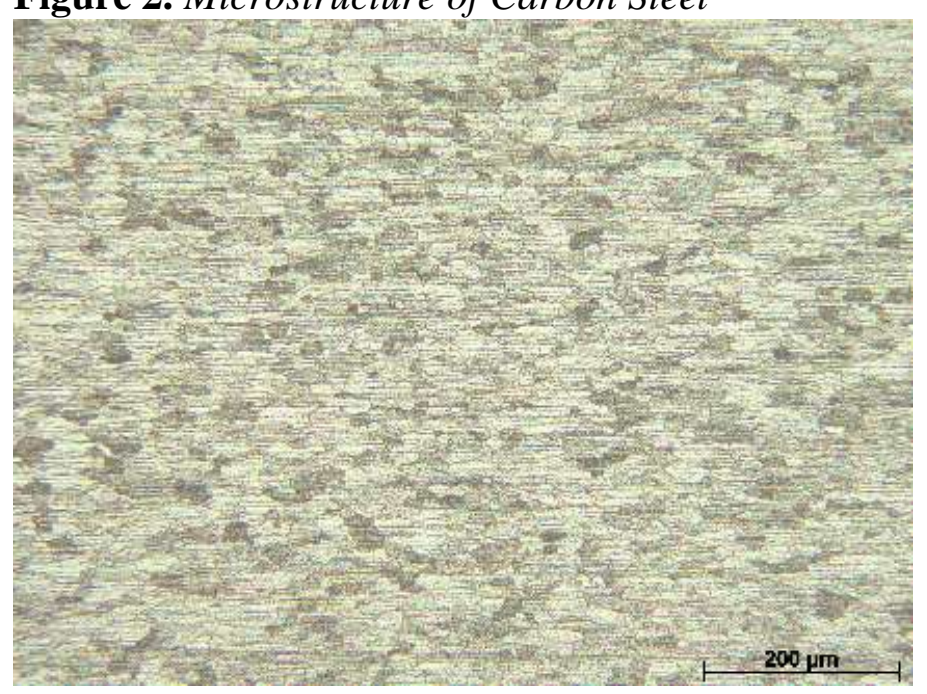

\footnotetext{
${ }^{1}$ http://www.concretecountertopinstitute.com/the-importance-of-watercement-ratio/. ${ }^{2}$ https://online.ferona.cz/detail/23985/plech-valcovany-za-studena-k-tvareni-za-studena-en-10 131-rozmer-2x1250x2500.
} 


\section{Electrochemical Measurements}

\section{For Testing in Model Solutions}

Polypropylene corrosion cells were fastened onto the non-corroded steel specimens. The cells were filled with different solutions (approximately $5 \mathrm{ml}$ ) one after the other. Firstly, saturated calcium hydroxide solution and calcium carbonate, or both solutions were used. After 24 hours, the corrosion cells were emptied and filled with a new solution that differs only in chloride anions content. After another 24 hours, the solution was replaced by a new solution, which contained chloride anions and a corrosion inhibitor.

At the defined time interval, after 24 hours after the corrosion cells were filled with the solution, the polarization resistance was measured as shown in Figure 3. A reference electrode with the counter electrode was immersed in the solution. The reference electrode was a saturated calomel electrode (SCE) and platinum wire (CE) was used as the counter electrode. The exposed area was $2.81 \mathrm{~cm}^{2}$. The polarization resistance was measured within $\pm 20 \mathrm{mV}$ from an open circuit potential $\left(\mathrm{E}_{\mathrm{oc}}\right)$ with a scan rate of $0.1 \mathrm{mV} / \mathrm{s}$. The polarization resistance value was then determined from the slope of the curve within $\pm 5 \mathrm{mV}$ from $\mathrm{E}_{\mathrm{oc}}$. Among the measurements, the corrosion cells were closed to prevent carbon dioxide from being absorbed from the air. The resulting polarization resistance value was determined an average of five measurements. Inaccuracies of individual measurements were displayed as error bars in graphics processing.

\section{Figure 3. Configuration of the Corrosion Cells}

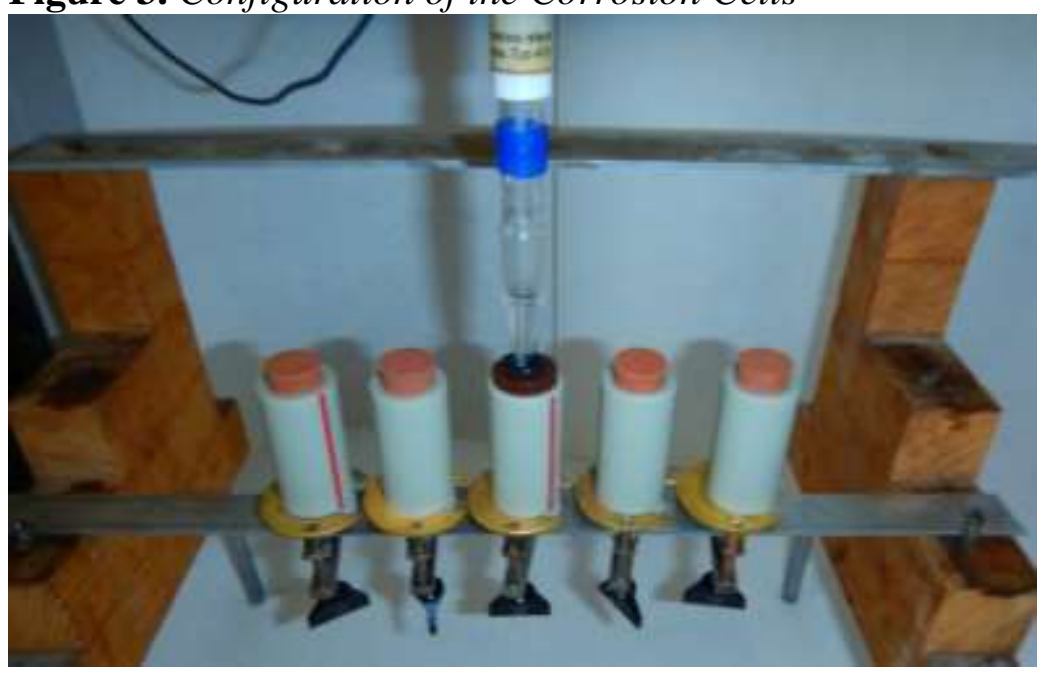

Testing of Migration Ability

The concrete specimen was fixed in between two chambers with the volume of 0.5 liters. Stainless steel mesh were built in the chamber parallel to both flat surfaces of the concrete specimen at a distance of approximately $3 \mathrm{~mm}$, as shown in Figure 4. 
Figure 4. Experimental Cell for Electrochemical Treatment

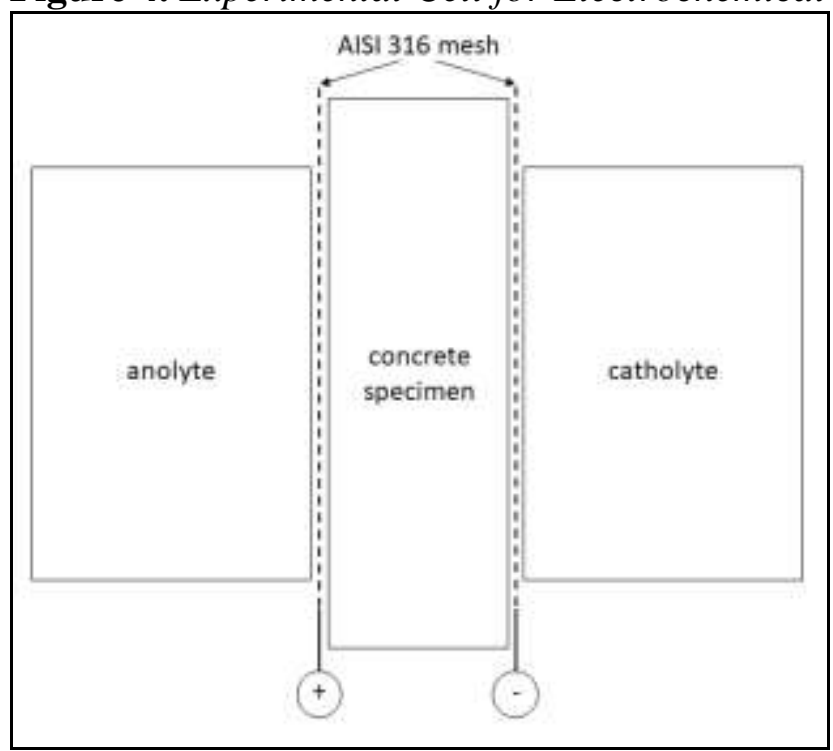

The catholyte chamber (Figure 5, right side) was filled with $3 \% \mathrm{NaCl}$ solution and the anolyte chamber was filled with solution of corrosion inhibitors. Galvanostatic mode was used for electrochemical injection of corrosion inhibitor with simultaneous electrochemical chloride extraction. Constant current with values of $2.53 \mathrm{~mA}$ and $16.65 \mathrm{~mA}$ was applied between stainless steel mesh electrodes for 7 days. These values correspond to current density of $1 \mathrm{~A} \cdot \mathrm{m}^{-2}$ or 5 A.m ${ }^{-2}$. Constant current was introduced by a Radelkis OH-404/A potentiostat, which was used as galvanostat. The current flow was measured with a METEX M 3650 multimeter and recorded with a METEX Control Software Client every 5 minutes. The resulting voltage was recorded using a IEC1010-1 voltmeter. In addition to the migration tests, the so-called plain diffusion was performed. The diffusion experiment was set exactly in the same way as the electrochemical injection, but no current was used.

Figure 5. 3D Model of Corrosion Cell

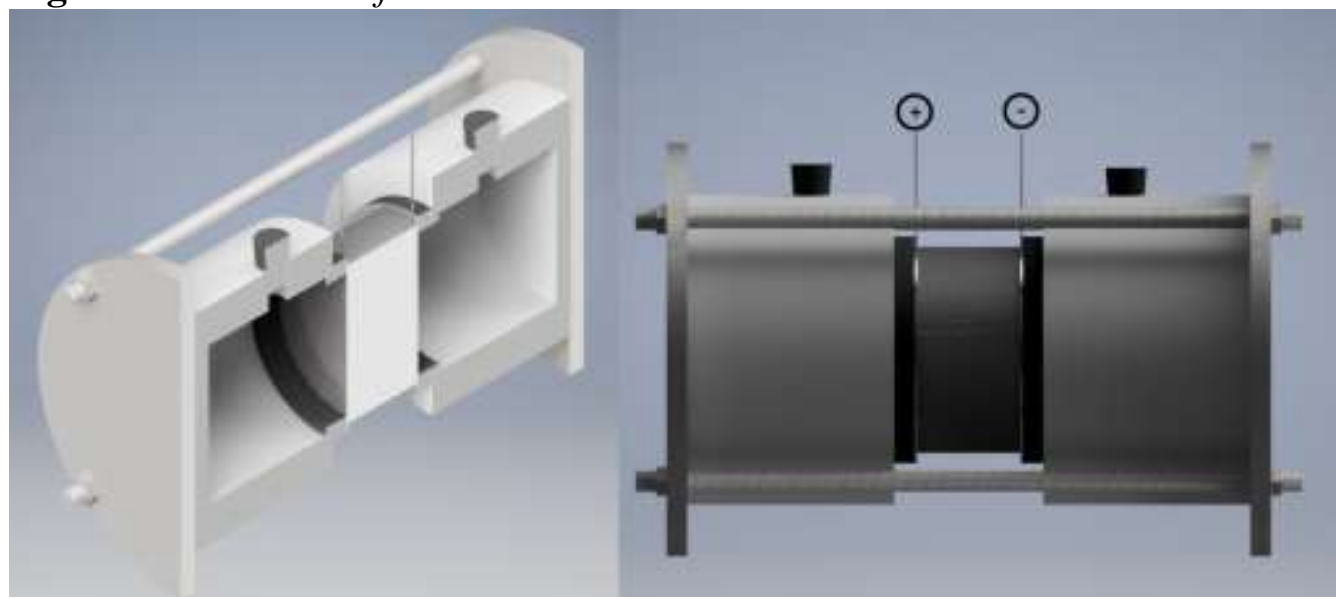




\section{Analysis Method}

After the injection and/or extraction or diffusion, two $5 \mathrm{~mm}$ thick slices were taken from the catholyte side of the concrete cylinder. Three $5 \mathrm{~mm}$ thick slices were taken from the anolyte side (Figure 6). The concentration profile of the injected corrosion inhibitor and chloride anions was determined by analysing these slices. The slices were pulverized using a laboratory mill. The powder was dried at $80{ }^{\circ} \mathrm{C}$ overnight. 20 grams of the powder was then mixed with $50 \mathrm{ml}$ of distilled water and the mixture was ultrasonicated for one hour. The liquid phase was separated from the solid by means of centrifugation and analyzed. The guanidine concentration was determined using a mass spectrometer, LC-MS LTQ-Orbitrap Velos. The chloride concentration was determined using an absorption spectrophotometer, FIA lab 2000. The concentration profile obtained by electrochemical injection was compared with that resulting from a plain diffusion.

Figure 6. The Analyzed Parts of the Sample

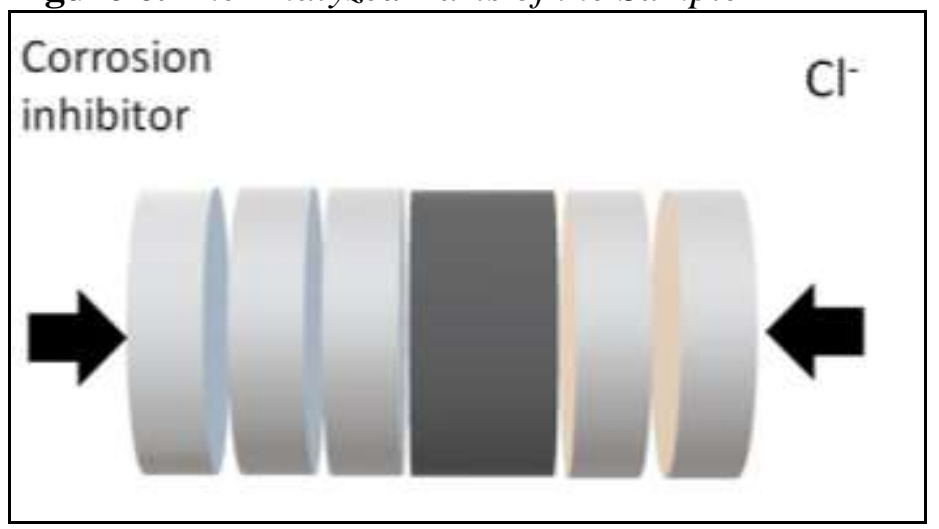

\section{Results and Discussion}

\section{Polarization Resistance}

\section{Calcium Hydroxide Solution}

In solution simulating fresh concrete, the polarization resistance values were in tens of $\Omega . \mathrm{m}^{2}$. Such high values indicate the passive state of carbon steel in chloride-free model solution. The values of the open circuit corrosion potential also correspond to the passive state of the steel. Negligible corrosion rate is thus expected. After addition of the chloride anions to the base solution, the polarization resistance values are declined by an order of magnitude, as shown in Figure 7. 
Figure 7. Fresh Concrete Pore Solution with Two Levels of Corrosion Inhibitors and $15 \mathrm{~g} . \mathrm{l}^{-1} \mathrm{Cl}^{-}$

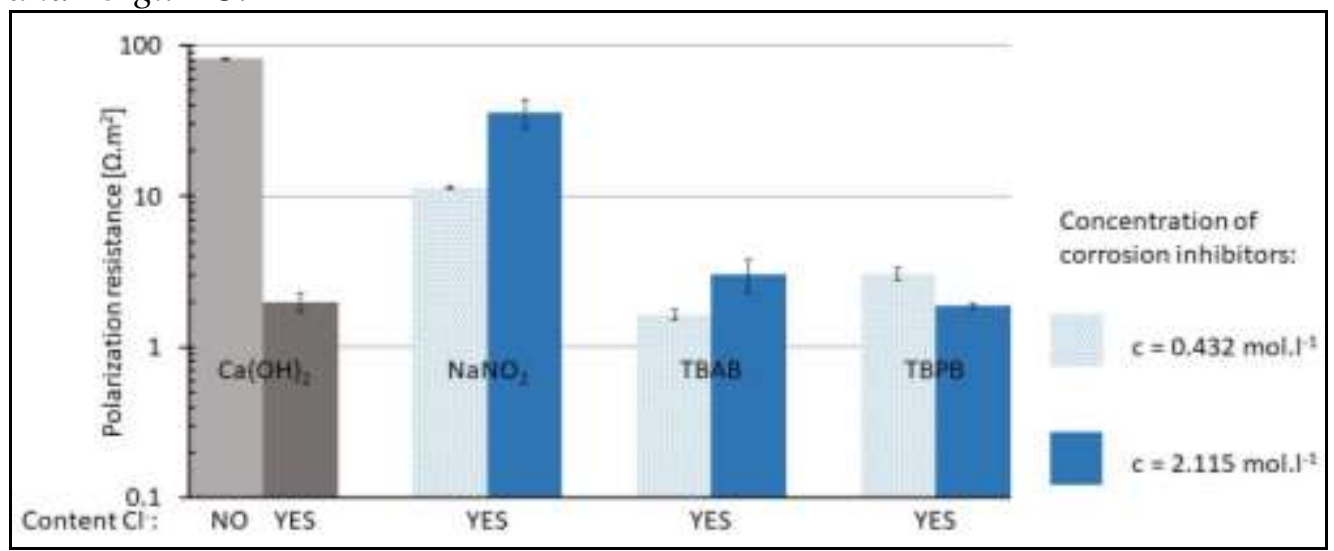

The decrease in the values of the polarization resistance was followed by a decrease in the open circuit corrosion potential; the values of which shifted to negative values. By adding a corrosion inhibitor to solution containing chloride anions, it was assumed that the passive state of the steel could be restored. When tetrabutylammonium bromide (TBAB) was applied at a 1:1 concentration, no significant increase in polarization resistance was recorded. When increasing the corrosion inhibitor concentration five times, there was a slight increase in polarization resistance, but this increase was only two-fold compared to the previous concentration. Using tetrabutylphosphonium bromide (TBPB), the opposite effect was observed. At a higher concentration of corrosion inhibitor, the polarization resistance decrease by one third. The low polarization resistance values for both tetrabutylammonium bromide and tetrabutylphosphonium bromide responded to open circuit corrosion potential values ranging from $-490 \mathrm{mV}$ to -570 $\mathrm{mV}$ (Figure 8).

Figure 8. Open Circuit Potential for Fresh Concrete Pore Solution with Content Corrosion Inhibitors and Chloride Ions

\begin{tabular}{|c|ccc|c|}
\hline ContentCl: & NO YES & YES & YES & \\
\\
\end{tabular}




\section{$\underline{\text { Calcium Carbonate Solution }}$}

As expected, the calcium carbonate solution activates the steel immediately after the start of the experiment. The reason is the low $\mathrm{pH}$ of the solution as compared to the calcium hydroxide solution. In this solution, steel does not have the ability to form a protective layer composed of stable oxide on its surface; thus, depassivation was observed as shown in Figure 9. The value of polarization resistance decreases to multiples of $10^{0}$ of $\Omega \cdot \mathrm{m}^{2}$ in this environment without corrosion inhibitor. When the chloride ions content increase, the polarization resistance decreased to lower values than those measured with the basic solution. However, when corrosion inhibitors were added to the basic solution, the value of polarization resistance slightly increased. However, there was no significant change in polarization resistance values. After addition of the chloride anions in concentration $0.1 \mathrm{~g} .1^{-1}$ to the calcium carbonate solution with content corrosion inhibitor, a slight decrease in the values of the polarization resistance for tetrabutylammonium bromide was observed, while a slight rise in the polarization resistance values was observed in the case of tetrabutylphosphonium bromide.

Figure 9. Polarization Resistance of Steel in Carbonated Concrete Pore Solution with Content 0.1 g.l $l^{-1}$ Chlorides

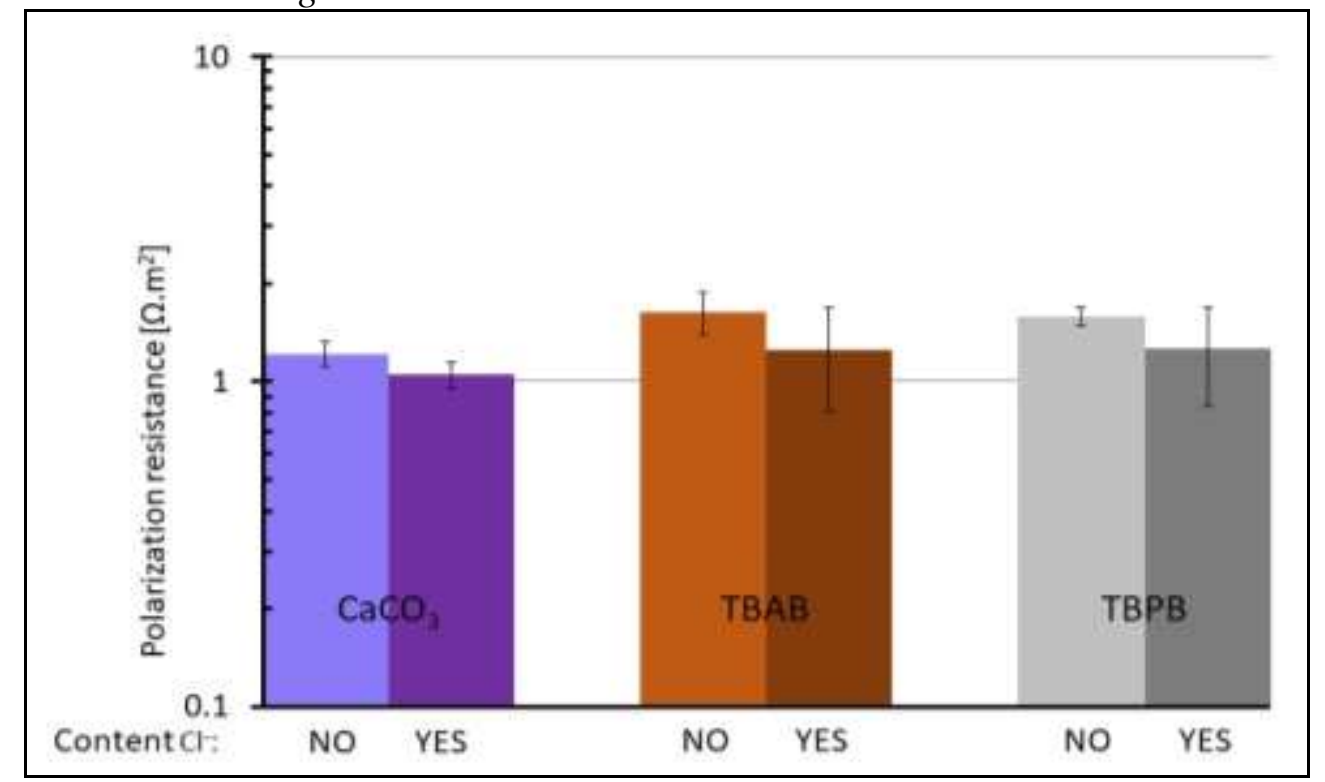

The gradual increase in chloride ion concentration $\left(1 \mathrm{~g}^{-1} \mathrm{l}^{-1}\right)$ in calcium carbonate solution resulted in a decrease in the polarization resistance value of both the basic solution and the tetrabutylammonium bromide (Figure 10). However, the values of the polarization resistance of tetrabutylphosphonium bromide remained constant at the concentration of chloride anions of $1 \mathrm{~g} \cdot \mathrm{l}^{-1}$ as well as in $0.1 \mathrm{~g}^{-1} \mathrm{l}^{-1}$. However, after increasing the concentration of chloride ions tenfold, none of the inhibitors tested showed significant polarization resistance (Figure 11). However, some inhibition was detected. What remains unanswered is whether the transport of such a corrosion inhibitor might be accelerated by 
electrochemical injection into chloride contaminated and/or carbonated concrete while chlorides are being extracted from the concrete and/or the concrete surrounding the depassivated steel realkalizes. Another question is whether its effectiveness increases when chloride ions are removed from the surface of the steel using electrochemical extraction.

Figure 10. Polarization Resistance of Steel in Carbonated Concrete Pore Solution with Content 1 g. $l^{-1}$ Chlorides

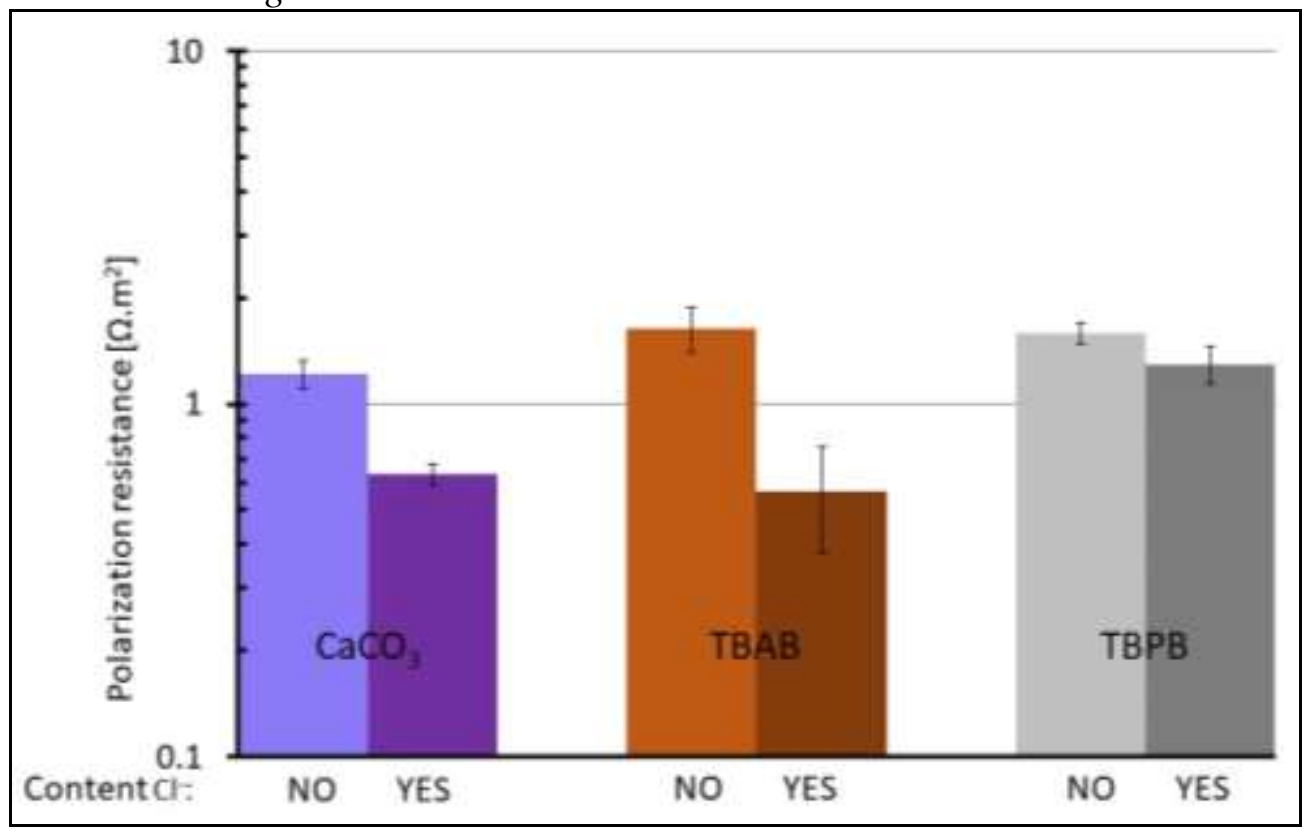

Figure 11. Polarization Resistance of Steel in Carbonated Concrete Pore Solution with Content $10 \mathrm{~g} . \mathrm{l}^{-1}$ Chlorides

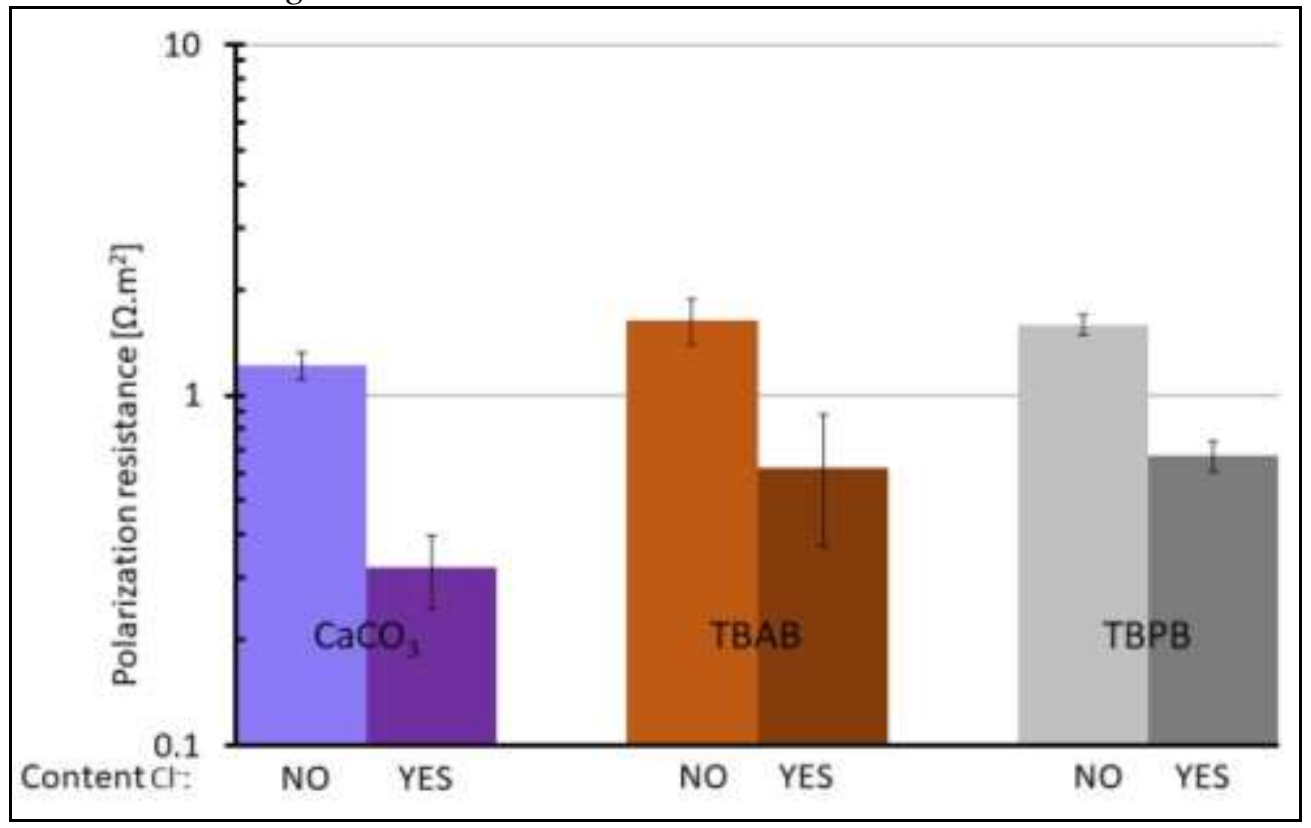




\section{Migration Ability}

\section{Chloride Extraction}

The process of chloride extraction (Figures 12 and 13) has been significantly affected by the use of an electric field. While in the test of plain diffusion, the concentration values were low, (was in the other of $10^{0} \mathrm{mmol}^{-1} \mathrm{I}^{-1}$; concentration of chloride ions or inhibitor in the extract). Using tetrabutylammonium bromide, the concentration of chloride ions after the diffusion test is low and uniform throughout the whole sample. Using tetrabutylphosponium bromide the increase chloride concentration was detected only in the surface layer and further sections contained only the original amount of chloride ions. An increase values of concentration of chloride ions to tens mmol. $\mathrm{l}^{-1}$ occurred, when current density 1 and $5 \mathrm{~A} \cdot \mathrm{m}^{-2}$ was applied. At a current density of $1 \mathrm{~A} \cdot \mathrm{m}^{-2}$, the concentration was significantly higher at the surface layer of the sample compared to diffusion for both corrosion inhibitors. However, at a depth of $35 \mathrm{~mm}$ or more, the concentration of chloride ions was very similar to those detected after diffusion. At the highest current density used, chloride ions were able to get through the whole sample at a relatively high concentration, up to approximately, $7 \mathrm{mmol} . \mathrm{l}^{-1}$. By using this current density, it was possible to get the largest amount of chloride ions through the sample.

Figure 12. Concentration Profile of $\mathrm{Cl}^{-}$after Application of TBAB

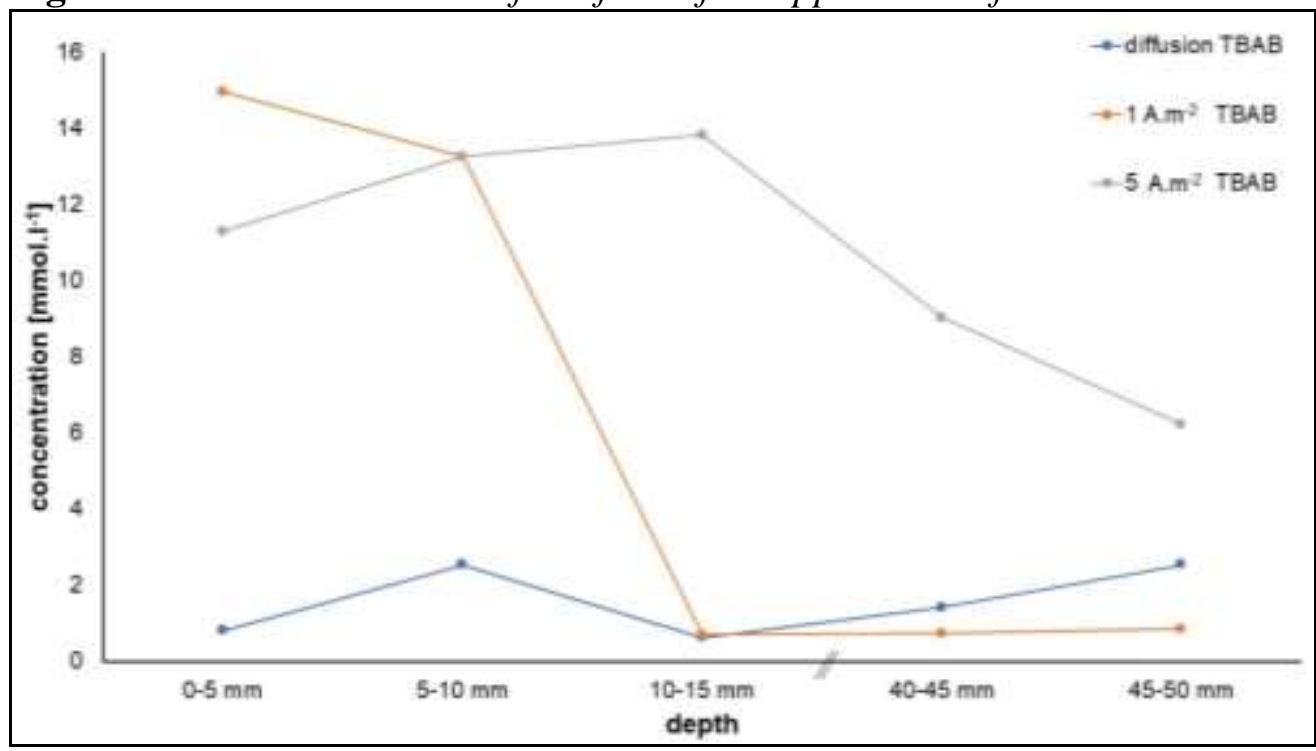


Figure 13. Concentration Profile of $\mathrm{Cl}^{-}$after Application of TBPB

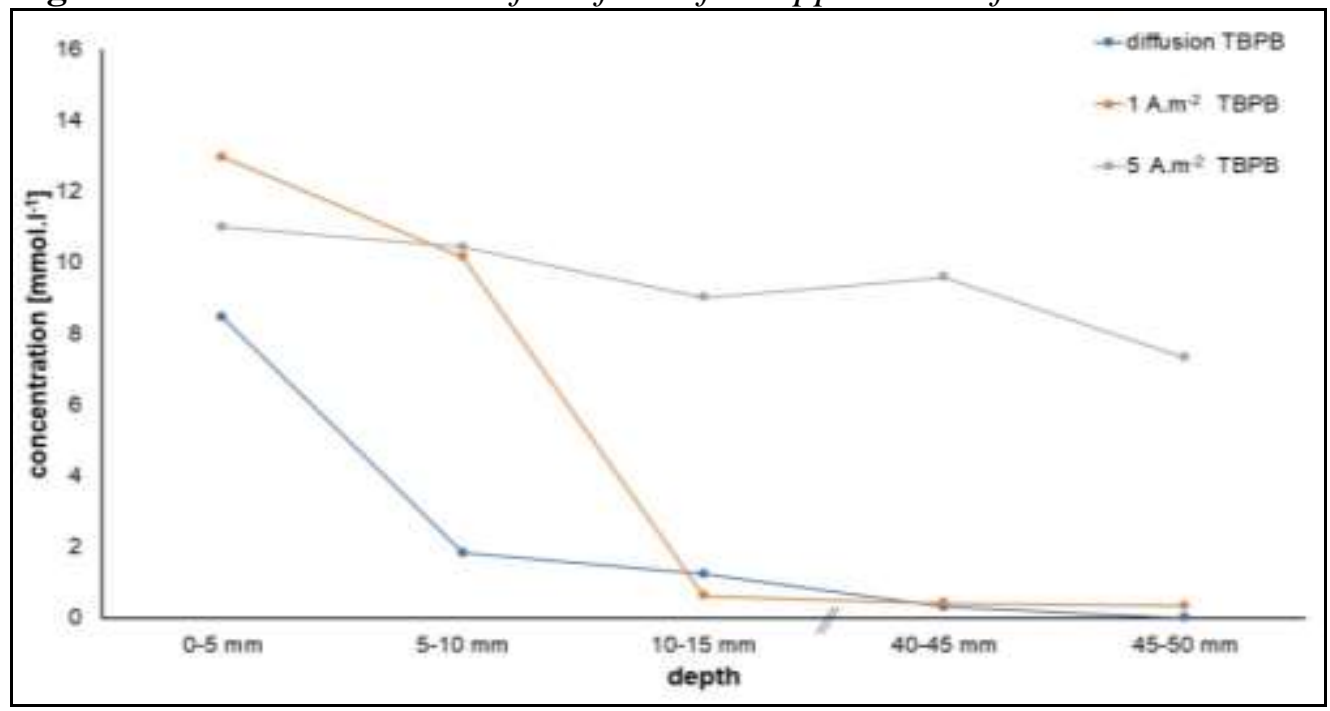

$\underline{\text { Injection of Corrosion Inhibitors }}$

With regard to tetrabutylammonium bromide, it was injected only within 10 to $15 \mathrm{~mm}$ of the sample surface. At greater depth, the inhibitor was not detected. Figures 14 to 16 show the concentration profiles for the particular test methods. As mentioned, the samples were subjected to electrochemical chloride extraction with simultaneous electrochemical injection of a corrosion inhibitor for seven days. As can be seen, during diffusion (Figure 14), the inhibitor concentration on the surface of the sample is quite high, but the tetrabutylphosphonium bromide concentration is almost five times smaller. From the surface, the concentration decreases rapidly (at tetrabutylammonium bromide) and is almost undetectable in the other sections.

Figure 14. Concentration Profile of TBAB and TBPB after Diffusion for Seven Days

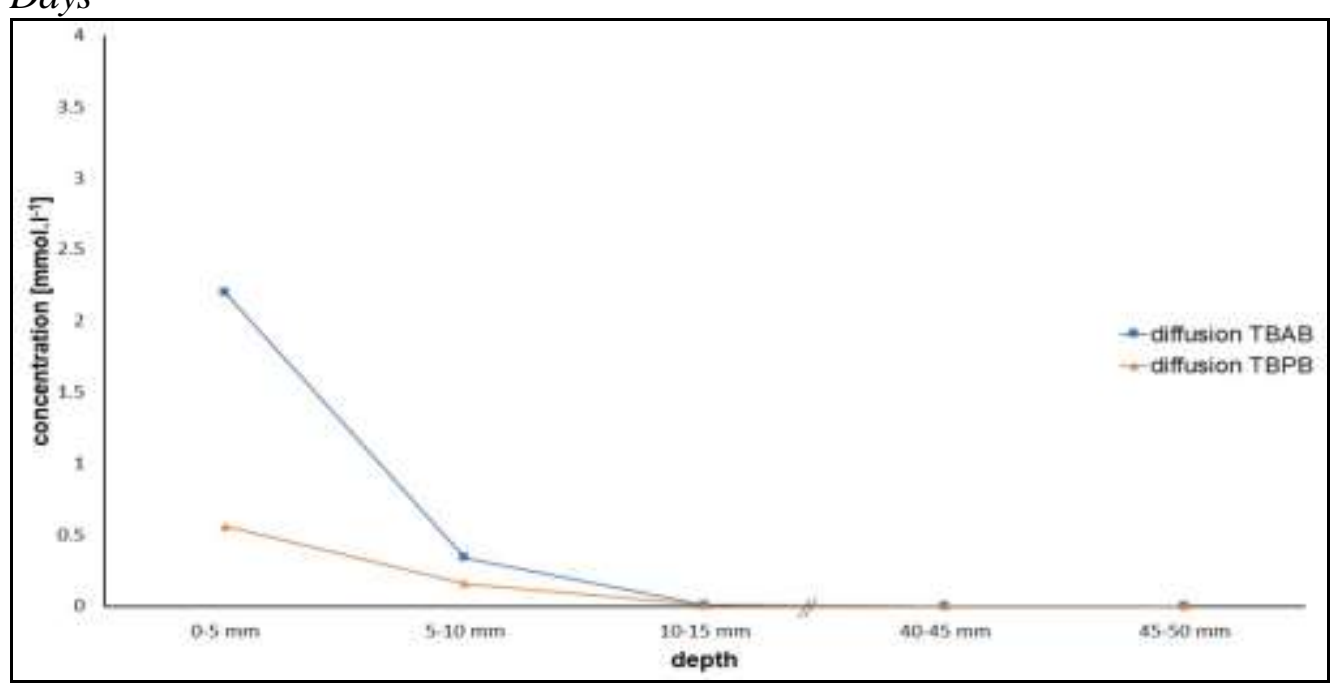


When using a current density of 1 A.m ${ }^{-2}$, the concentration of tetrabutylammonium bromide on the surface of the sample is almost two times higher compared to diffusion (Figure 15). Considering only diffusion, better results were obtained in the case of tetrabutylammonium bromide. Using a current density of 1 A.m ${ }^{-2}$, there was no significant change when using the tetrabutylphos-phonium bromide. The concentration of the inhibitor was very similar to the application without an electric field. In the second and third sections, the concentration gradually decreases.

Figure 15. Concentration Profile of $T B A B$ and $T B P B$ after Application Current Density 1 A. $\mathrm{m}^{-2}$ for Seven Days

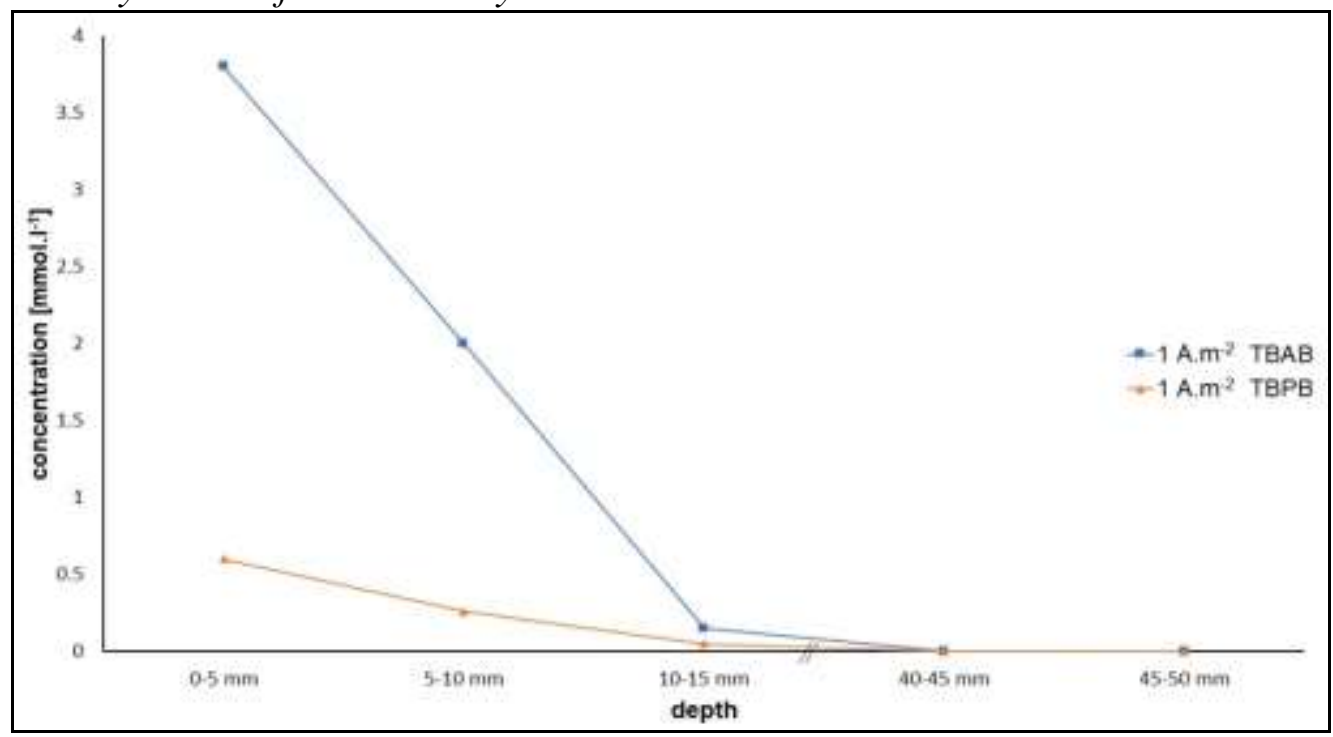

Figure 16. Concentration Profile of TBAB and TBPB after Application Current Density 5 A.m $\mathrm{m}^{-2}$ for 7 Days

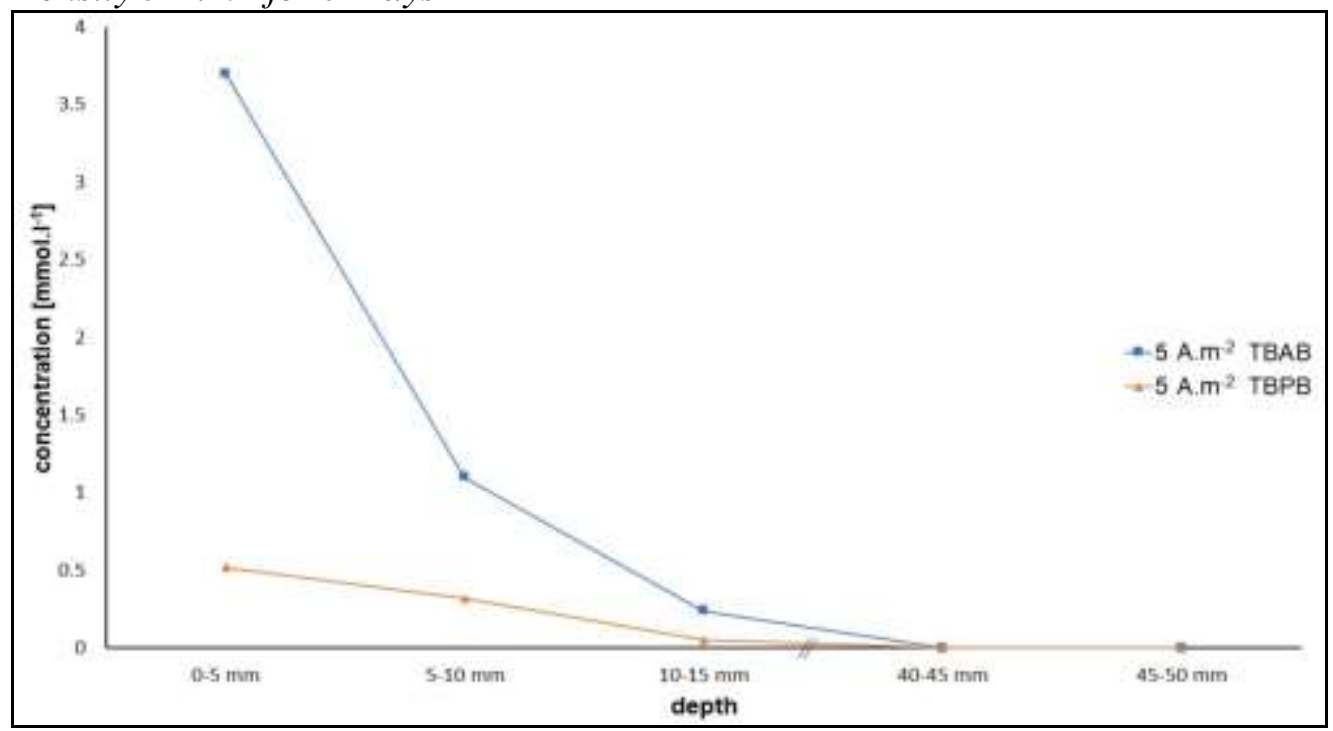


The transport was not significantly affected by migration, when the current density of 5 A.m ${ }^{-2}$ was used (Figure 16). The inhibitors were also identified in a section 10 to $15 \mathrm{~mm}$ distant from the concrete surface. The results proved that tetrabutylammonium bromide is transportable by migration in fresh concrete, but for tetrabutylphosphonium bromide this property was not proven. With respect to the tetrabutylphosphonium bromide, no significant changes have been observed here, either in spontaneous diffusion or in the application of the electric field. The values of concentration of tetrabutylphosphonium bromide were approximately the same for all three methods tested.

\section{Conclusions}

Electrochemical measurements have demonstrated low efficiency of both corrosion inhibitors. Nevertheless, better results were achieved using TBAB. The behavior of this inhibitor in a pore solution of fresh concrete was better compared to TBPB. TBAB reached higher polarization resistance values at increased concentration. It is assumed, that the inhibitor's effectiveness was influenced by the presence of bromides, which have similar effect as chloride anions. Since bromide belongs to the group of aggressive elements, it is also $\mathrm{Cl}$ or $\mathrm{S}$. These may result in more aggressive substances in the solution which interfere with the formation of a passive layer on the steel surface. The final result is therefore a solution of $0.423 \mathrm{~mol}^{-1} \mathrm{l}^{-1}$ of bromides to which $\mathrm{Cl}$ is still attached.

In the second part, tetrabutylammonium and tetrabutylphosphonium cathions have demonstrated their ability to migrate in the alkaline environment of concrete. Their transport can be efficiently accelerated by the action of an electric field where the anode is placed on the surface of the reinforced concrete structure in the inhibitor solution and the cathode is a steel reinforcement in the chloride contaminated concrete. At the same time, electrochemical injection of a corrosion inhibitor and electrochemical extraction of chlorides may occur. The lowest increase in inhibitor concentration in concrete was observed in the case of tetrabutylphosphonium cation, using a current density of 1 and $5 \mathrm{~A} \cdot \mathrm{m}^{-2}$. On the other hand, the largest concentration was observed in the case of tetrabutylammonium cation, when the concentration of corrosion inhibitor in the surface layer was approximately four times higher in comparison with tetrabutylphosphonium.

\section{Acknowledgments}

The authors gratefully acknowledge the support by the Czech Science Foundation in the frame of the research project 16-11879S. 


\section{References}

Angst, U., et al. Critical chloride content in reinforced concrete - A review. Cement and Concrete Research. 2009. vol. 39, no. 12, pp. 1122-1138.

Asaro, M. F., et al. Electrochemical chloride removal and protection of concrete bridge components (injection of synergistic corrosion inhibitors). No. SHRP-S-310. 1990. pp. 53.

Carmona, J., et al. Shape Effect Of Electrochemical Chloride Extraction In Structural Reinforced Concrete Elements Using A New Cement-Based Anodic System. Materials. 2015. vol. 8, pp. 2901-2917.

Daniyal, Md. and Raja, Md. A. Use of Corrosion Inhibitors for Steel Protection in Cementitious Composites-A Review. 2016. vol. 3, no. 6, pp. 171-175.

Elsener, B. and Angst, U. Mechanism of electrochemical chloride removal. Corrosion Science. 2007. vol. 49, no. 12, pp. 4504-4522.

Fajardo, G., Escadeillas, G., Arliguie, G. Electrochemical chloride extraction (ECE) from steel-reinforced concrete specimens contaminated by "artificial" sea-water. Corrosion Science. 2006. vol 48, no. 1, pp. 110-125.

Gaidis, J. M. Chemistry of corrosion inhibitors. Cement and Concrete Composites. 2004. vol. 26, no. 3, pp. 181-189.

García, J., et al. Effect of cathodic protection on steel-concrete bond strength using ion migration measurements. Cement and Concrete Composites. 2012. vol. 34, no. 2, pp. 242-247.

Gong, J., et al. Electrochemical Chloride Extraction and Inhibitor Injection in SaltContaminated Repair Mortar. International Journal of Electrochemical Science. 2018. vol. 13, pp. 498-513.

Herrera, J. C., Escadeillas, G., Arliguie, G. Electro-chemical chloride extraction: Influence of $\mathrm{C}_{3} \mathrm{~A}$ of the cement on treatment efficiency. Cement and Concrete Research. 2006. vol. 36, pp. 1939-1946.

Ihekwaha, N. M., Hope, B. B., Hansson, C. M. Carbonation and electrochemical chloride extraction from concrete. Cement and Concrete Research. 1996. vol. 26, vo. 7, pp. 1095-1107.

Karthick, S. P., et al. Electrochemical process to improve the durability of concrete structures. Journal of Building Engineering. 2016. vol. 7, pp. 273-280.

Kouril, M., Lovasi, T., Msallamova, S., Nemecek, J., Sulc, R. Electrochemical injection of cathionic corrosion inhibitors. In ACSEE 2017. Sixth International Conference on Advances in Civil, Structural and Environmental Engineering. Rome, 2017. pp. 4044.

Kubo, J., et al. Electrochemical inhibitor injection for control of reinforcement corrosion in carbonated concrete. Materials and Corrosion. 2008. vol. 59, no. 2, pp. 107-114.

Kubo, J., Tanaka, Y., Page, C. L., Page, M. M. Application of electrochemical organic corrosion inhibitor injection to a carbonated reinforced concrete railway viaduct. Construction and Building Materials. 2013. vol. 39, pp. 2-8.

Li, L. Y. and Page, C. L. Finite element modelling of chloride removal from concrete by an electrochemical method. Corrosion Science. 2000. vol. 42, pp. 2145-2165.

Liu, Y. and Shi, X. Electrochemical chloride extraction and electrochemical injection of corrosion inhibitor in concrete: state of the knowledge. Corrosion Reviews. 2009. vol. 27, no. 1-2, pp. 53-822.

Lovasi, T., Msallamova, S., Kouril, M., Jamborova, T., Stoulil, J., Nemecek, J., Sulc, R. Cathionic corrosion inhibitors for protection of steel in chloride contaminated 
concrete. In METAL 2017: 26rd International Conference on Metallurgy and Materials. Brno, 2017, pp. 1361-1367.

Miranda, J. M. et al. Several questions about electrochemical rehabilitation methods for reinforced concrete structures. Corrosion Science. 2006. vol. 48, no. 8, pp. 2172-2188.

Miranda, J. M., et al. Limitations and advantages of electrochemical chloride removal in corroded reinforced concrete structures. Cement and Concrete Research. 2007. vol. 37, no. 4, pp. 596-603.

Martinez, I., et al. Chloride Electroremediation in reinforced structures: preliminary electrochemical tests to detect the steel repassivation during the treatment. Electrochimica Acta. 2015. vol. 181, pp. 288-300.

Nguyen, T. H., et al. Effect of Electrical Injection of Corrosion Inhibitor on the Corrosion of Steel Rebar in Chloride-Contaminated Repair Mortar. International Journal of Corrosion. 2015. vol. 2015, pp. 1-10.

Orellan, J. C., G. Escadeillas, G. Arliguie. Electrochemical chloride extraction: efficiency and side effects. Cement and Concrete Research. 2004. vol. 34, no. 2, pp. 227-234.

Ormellese, M., et al. A study of organic substances as inhibitors for chloride-induced corrosion in concrete. Corrosion Science. 2009. vol. 51, no. 12, pp. 2959-2968.

Page, C. L., et al. The influence of different cements on chloride-induced corrosion of reinforcing steel. Cement and Concrete Research. 1986. vol. 16, pp. 79-86.

Pan, T., Nguyen, T. A., Shi, X. Assessment of Electrical Injection of Corrosion Inhibitor for Corrosion Protection of Reinforced Concrete. TRB Annual Meeting 2008, Washington D.C.

Parthiban, G. T., et al. Cathodic protection of steel in concrete using magnesium alloy anode. Corrosion Science. 2008. vol. 50, no. 12, pp. 3329-3335.

Pedeferri, P. Cathodic protection and cathodic prevention. Construction and Building Materials. 1996. vol. 10, no. 5, pp. 391-402.

Sawada, S., Page, C. L., Page, M. M. Electrochemical injection of organic corrosion inhibitors into concrete. Corrosion Science. 2005. vol. 47, no. 8, pp. 2063-2078.

Sawada, S., et al. Electrochemical injection of organic corrosion inhibitors into carbonated cementitious materials: Part 1. Effects on pore solution chemistry. Corrosion Science. 2007. vol. 49, no. 3, pp. 1186-1204.

Shi, X., et al. Longevity of corrosion inhibitors and performance of liquid deicer products under field storage. Canadian Journal of Civil Engineering. 2012. vol. 39, no. 2, pp. 117-127.

Söylev, T. A. and M. G. Richardson. Corrosion inhibitors for steel in concrete: State-ofthe-art report. Construction and Building Materials. 2008. vol. 22, no. 4, pp. 609-622.

Vavpetič, V. Corrosion in concrete steel, seminar. University of Ljubljana, Faculty of mathematics and physics. 2008.

$\mathrm{Xu}$, J., Yao, W. Electrochemical studies on the performance of conductive overlay material in cathodic protection of reinforced concrete. Construction and Building Materials. 2011. vol. 25, no. 5, pp. 2655-2662.

$\mathrm{Xu}, \mathrm{C}$., et al. Organic corrosion inhibitor of triethylenetetramine into chloride contamination concrete by eletro-injection method. Construction and Building Materials. 2016. vol. 115, pp. 602-617.

Yeih, W., Chang, J. J., Hung, C. C. Selecting an adequate procedure for the electrochemical chloride removal. Cement and Concrete Research. 2006. vol. 36, no. 3, pp. 562-570. 
